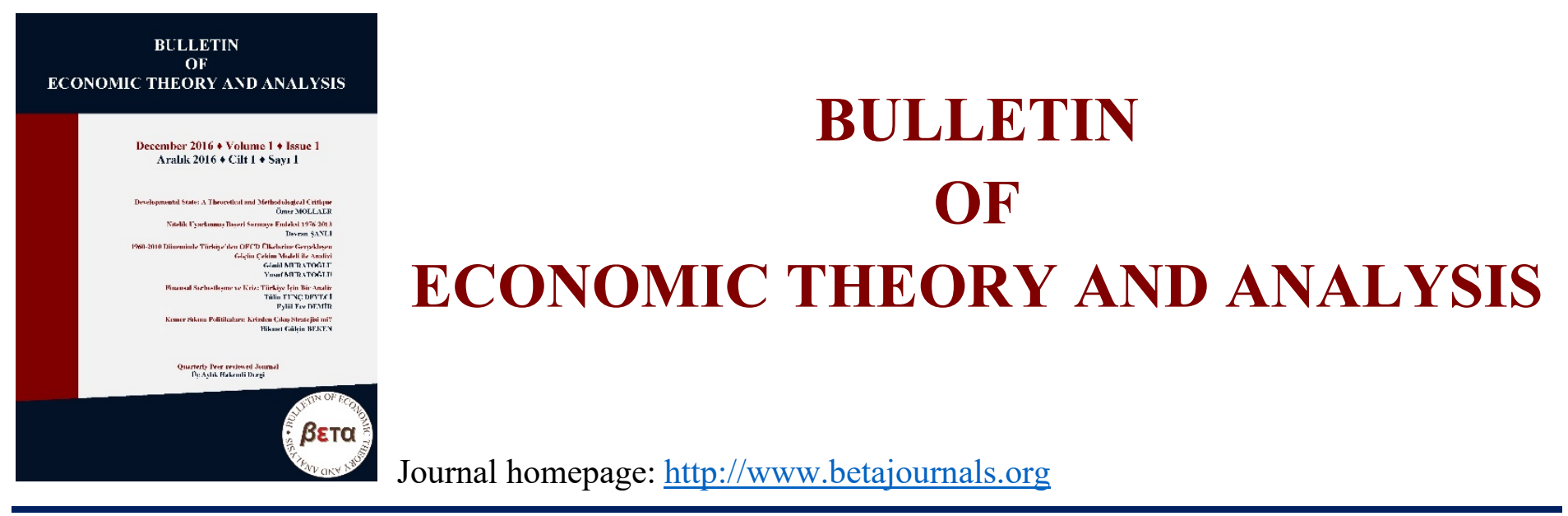

\title{
The Effect of Behavioral Risk Factors on Healthcare System Performance
}

Mehmet Emin KURT $\odot$ https://orcid.org/0000-0002-7068-2807

Cuma ÇAKMAK ำ https://orcid.org/0000-0001-8750-652X

Murat KONCA $\odot$ https://orcid.org/0000-0001-5622-6250

İsmail BİÇER $\odot$ https://orcid.org/0000-0003-4763-9314

To cite this article: Kurt, E., M., Çakmak, C., Konca, M. \& Biçer, İ. (2020). The Effect of Behavioral Risk Factors on Healthcare System Performance. Bulletin of Economic Theory and Analysis, 6(1), 114.

Received: 25 Nov 2020

Accepted: 11 Feb 2021

Published online: 24 May 2021

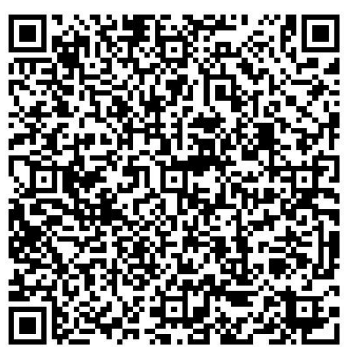




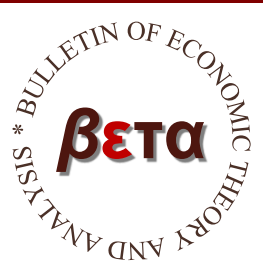

\title{
Bulletin of Economic Theory and Analysis
}

Volume VI, Issue 1, pp. 1-14, 2021

http://www.betajournals.org

Original Article / Araştırma Makalesi

Received / Alınma: 25.11.2020 Accepted / Kabul: 11.02.2021

\section{The Effect of Behavioral Risk Factors on Healthcare System Performance}

\author{
Mehmet Emin KURT ${ }^{\mathrm{a}}$ \\ Cuma ÇAKMAK ${ }^{\mathrm{b}}$ \\ Murat $\mathrm{KONCA}^{\mathrm{c}}$ \\ İsmail BİÇER ${ }^{\mathrm{d}}$
}

${ }^{a}$ Dr. Öğr. Üyesi, Dicle Üniversitesi, İktisadi ve İdari Bilimler Fakültesi, Sağlık Yönetimi Bölümü, Diyarbakır, TÜRKIYE @ https://orcid.org/0000-0002-7181-8681

b Arş. Gör., Dicle Üniversitesi, İktisadi ve İdari Bilimler Fakültesi, Sağlık Yönetimi Bölümü, Diyarbakır, TÜRKIYE ○ https://orcid.org/0000-0002-4409-9669

${ }^{c}$ Arş. Gör., Hacettepe Üniversitesi, İktisadi ve İdari Bilimler Fakültesi, Sağlık Yönetimi Bölümü, Ankara, TÜRKIYE $\odot$ https://orcid.org/0000-0002-6830-8090

d Öğr. Gör., İstanbul Arel Üniversitesi, Meslek Yüksekokulu, İstanbul, TÜRKİYE

ㄴ. https://orcid.org/0000-0003-1878-0546

\section{ABSTRACT}

Behavioural risk factors are known to have an impact on countries' health system performance. Behavioral risk factors include habits such as alcohol consumption, smoking, and patterns of food consumption which might lead to different types of obesity among different age groups in every community. In the context of OECD countries, this study aims at investigating whether behavioral risk factors have an impact on healthcare system performance or not. Data Envelopment Analysis (DEA) and then Ordinary Least Squares Regression (OLS) was utilized to bring into the open the factors that affect health performance scores of OECD countries. In OLS, the obtained health performance score was utilized as a dependent variable and alcohol and tobacco consumption and obesity rate were utilized as independent variables. According to the OLS results, The only variable that has a statistically significant effect on the health performance scores of OECD countries is the alcohol consumption rate. To reduce health expenditures and improve health system performance, OECD countries need to develop more effective, macro and micro, level policies to eliminate the negative effects of behavioral risk factors. Such policies might include health awareness campaigns and more strict taxing policies upon the risk factor products, in addition to increasing community-based healthcare services.

Keywords

Behavioral Risks

Factors,

Healthcare System

Performance, Efficiency of Healthcare Systems, Data Envelopment

Analysis,

Ordinary Least Squares Regression

JEL Classification $\mathrm{I} 00, \mathrm{I} 1, \mathrm{I} 12, \mathrm{I} 18$

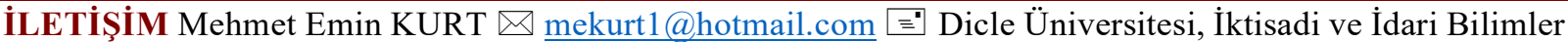
Fakültesi, Sağlık Yönetimi Bölümü, Diyarbakır, TÜRKIYE 


\section{Introduction}

The World Health Organization (WHO) indicates that drawing lines for healthcare systems is difficult and defines a healthcare system as "all activities with the primary purpose of promoting, restoring, and maintaining health." begins with a determination of their objectives (Kruk \& Freedman, 2008). In addition to providing quality and efficient health services, the fundamental objective of countries' healthcare systems also includes ensuring the optimum utilization of the resources for providing sound and robust health services (Caballer-Tarazona, Moya-Clemente, Vivas-Consuelo, Barrachina-Martínez, 2010). The main aim of healthcare systems is to provide the services that would ensure achieving good health and become responsive to the needs of the public in terms of the performance and the fair payment (Tyagi \& Singh, 2017). With the increase of population and the rise of the number of elderly in the developed countries, the role of responsive health services becomes increasingly more essential and new debates about the evaluation of the health systems and public administrations are often arising (Giannini, 2015). The importance of performance evaluation in health systems is increasing. Thus, the evaluation of the health care facility-performance should be of prime interest to governments, donor agencies as well as those who contribute in shaping and managing the healthcare system (Joachim \& Adeyemi, 2017). Because, the increasing costs of healthcare systems also increase medical care costs in nearly all countries and cause their respective governments to reconsider their approach to health policies and systems (Roberts, Hsiao, Berman \& Reich, 2008).

Regular comparisons of health care systems between countries can provide abundant evidence for countries, support national strategies in formulating national policy programs and priorities, and have a strong impact on the policies themselves (Papanicolas \& Smith, 2013). Therefore, the attention of countries is increasingly being directed towards the comparison of healthcare systems. Health care systems are compared based on several factors, which can be divided into two groups: supply and demand. While the increasing expectations of citizens affect the demand factors, supply factors are affected by developments in information Technologies (Roberts et al. 2008; Papanicolas \& Smith, 2013). As a result of the increase in attention to the evaluation of healthcare systems, many countries have developed national health databases or performance evaluation programs (Papanicolas \& Smith, 2013). The expectations of citizens from governments and healthcare systems are increasing. These expectations, which show an upward 
trend, are seen as the driving force behind health reforms and performance evaluations in many countries (Roberts et al., 2008)

It is already established that behavioral risk factors, such as tobacco use and excessive use of alcohol, undernutrition, and a sedentary lifestyle, increase the mortality rate of a population (Brown, Birtwistle, Roe \& Thompson, 1999). Noncommunicable diseases, such as cardiovascular diseases, cancer, diabetes, and respiratory diseases, are seen as the primary causes of death and are responsible for $70 \%$ of deaths around the world. It is known that noncommunicable diseases are caused by behavioral risk factors, such as tobacco use, undernutrition, a lack of physical activity, and the excessive use of alcohol, and that this causes overweight and obesity, eventually resulting in illness by increasing blood pressure and cholesterol. Noncommunicable diseases continue as an important health problem in all countries, including low and middle-income countries, where more than three-fourths of deaths due to this type of disease ocur (WHO, 2017). Behavioral risk factors, which are considered to be among the reasons behind noncommunicable diseases, can affect the performances of healthcare systems.

The assessment of the entire performance can be achieved by using different methods of evaluation. Such evaluation consists of identifying and determining the validity of programs and activities carried out (Nuti, 2008). The performance of healthcare systems is approached in a multidimensional way. Promoting a healthy lifestyle, however, constitutes another aspect of healthcare systems' performance. Although it constitutes a part of healthcare systems, international data showing the significance and benefits of promoting a healthy lifestyle is not clear. Most differences between countries are interpreted as relating to cultural factors rather than as efforts towards the promotion and development of health. For example, low alcohol consumption in Turkey probably stems from religious reasons. A systematic comparison of health education between countries is the first step that is required for the promotion of a healthy lifestyle in these countries (Anderson \& Hussey, 2001).

Performance measurement tools of health facilities and systems of all countries should be capable of improving management and ensuring prudent rationalization of resource allocation and mobilization of additional resources (Joachim \& Adeyemi, 2017). Conducting regular evaluations of the performances of healthcare systems with convenient measurement tools is significant for countries that aim to provide efficient, effective, and sustainable health services along with the 
primary objectives of providing quality, fair, and equal health services to their citizens. This study aims to determine countries' healthcare system performances and the extent to which behavioral risk factors affect them.

\section{Method}

\subsection{Type of the Study}

The research was made in descriptive type.

\subsection{The Universe and Sample of the Research, Data Collection Tools, Collecting Data, Evaluation of the Data}

In this study, the Data Envelopment Analysis (DEA) is utilized. In the study; the rate of health expenses in gross domestic product, the number of physicians per 1000 people, the number of nurses per 1000 people, the number of beds per 1000 people are used as input variables, and life expectancy at birth and infant mortality rate are used as output variables (Table 1). This study was conducted with 95\% confidence. The data were taken from the OECD database from 2016.

Table 1

Input and Output Variables Used in DEA

\begin{tabular}{llc}
\hline & Variables & Abbreviation \\
\hline & Health Expenditure/GDP ratio & Heir \\
& Physicians per 1000 people & Phy \\
& Nurses per 1000 people & Nur \\
& Beds per 1000 people & Bn \\
\hline & Life Expectancy at Birth for both sexes. & Leb \\
\hline
\end{tabular}

After the DEA was applied, the ordinary least squares regression (OLS) method was used by setting the DEA score as a dependent variable and the obesity rate and alcohol and tobacco consumption as independent variables (Table 2). In this way, analysis results were aimed at explaining the effect of the behavioral risk factor variables on the performances of countries' healthcare systems. 
Table 2

Dependent and Independent Variables Used in OLS

\begin{tabular}{|c|c|c|c|}
\hline \multicolumn{2}{|c|}{ Variables } & Explanation & Abbreviation \\
\hline \multirow{3}{*}{ 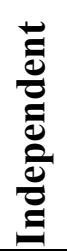 } & Tobacco & $\begin{array}{l}\text { The rate of daily tobacco use of the population above the } \\
\text { age of } 15\end{array}$ & Tobac \\
\hline & Obesity & Obesity Population Rate & Obes \\
\hline & Alcohol & $\begin{array}{l}\text { Annual alcohol sales per person for the people above the } \\
\text { age of } 15 \text {, by liter }\end{array}$ & Alch \\
\hline 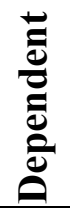 & $\begin{array}{l}\text { DEA } \\
\text { Score }\end{array}$ & $\begin{array}{l}\text { DEA results according to the input-oriented scale } \\
\text { belonging to OECD countries }\end{array}$ & DEA score \\
\hline
\end{tabular}

The data for the study were taken from the OECD database from 2016. The DEA-SOLVER13 Program was used for the DEA technique, and the EViews 9 Program was used for the OLS regression performed in this research. Information related to DEA and OLS is provided below.

DEA is a nonparametric analysis technique that is based on linear programming and used for the measurement of the efficiencies of decision-making units by using similar input and outputs. The basis of this method is introduced with the article named "Measuring the Efficiency of Decision-Making Units" by Charnes et al., (1978), Initially designed under the hypothesis of constant returns to scale (CRS or CCR) in the article in question, it was later changed to a form of variable returns to scale (VRS or BCC) created by Banker et al. (1984), The following can be said about the difference between CRS and VRS models: while the increase in input rates is expected to be the same as that of the output rates in the CRS model, a change in the output with a different ratio than the increase in the input rates is expected in the VRS model (Narc1, 2012). Additionally, the CRS model shows the total efficiency by including both the pure technical efficiency originating from the administrative performance and the scale efficiency originating from the size of the decision-making units. The VRS model, however, only shows pure efficiency by ignoring the size component (in other words, by excluding scale efficiency). As a result, the number of efficient decision variables is greater in a study where the VRS model is used than in a study using the CRS model (Narc1, 2012). If the DEA technique is used in a study, it should first be determined whether the DEA is input or output-oriented, and later, one of the models mentioned above (CRS or VRS) should be selected. The following can be said about input and output orientation (Charnes et al., 1981): 
- In an output orientation, when it is possible to increase output without increasing input and decreasing any other output, the decision-making units are evaluated as inefficient decision-making units.

- In an input orientation, when it is possible to decrease an input without increasing any other input and decreasing an output, the decision-making units are evaluated as inefficient decision-making units.

As can be inferred from the explanations above, in DEA, the factors determining whether a decision-making unit is efficient or inefficient may change, based on whether the CRS or VRS model is used in the analysis and if the analysis is input or output-oriented. In this study, the VRS model, consisting of input-oriented DEA, is employed. This study is input-oriented because, in areas such as healthcare systems where the planning and control of the outputs are quite difficult and managers have more control over the inputs, an input-oriented model is generally used (Sherman \& Zhu, 2006; Chern \& Wan, 2008). Also, the VRS model was chosen to evaluate the countries based on changes in pure technical efficiencies.

After DEA was applied to the scope of the study, an OLS regression model was created where the DEA score was the dependent variable, and tobacco use, obesity rates, and alcohol consumption were independent variables. In OLS regression models constant variance assumption is important in terms of the reliability of the OLS regression (Özcan, 2014; Stöckl, Dewitte \& Thienpont, 1998). Besides, in the OLS regression technique, the error terms (residuals) must be distributed normally, there must be no multicollinearity or autocorrelation problems, and the model must not have structural breaks. The tests performed in this study confirmed that the model constructed in this research does not have any of these problems. The results of these tests are presented in the Findings section.

\section{Findings}

In the present study, it was first investigated whether a high-level correlation between the variables used in DEA existed; based on the results of this inquiry, no high-level correlation (Table 3) was found. 
Table 3

Correlation Table of the Variables Used in DEA

\begin{tabular}{lcccccc}
\hline & Heir & Phy & Nur & Bn & Leb & Im \\
\hline Heir & 1 & & & & & \\
Phy & 0.22 & 1 & & & & \\
Nur & 0.58 & 0.16 & 1 & & & \\
Bn & -0.01 & -0.06 & 0.02 & 1 & & \\
Leb & 0.42 & 0.27 & 0.50 & 0.07 & 1 & \\
Im & 0.03 & 0.19 & 0.40 & 0.07 & 0.32 & 1 \\
\hline
\end{tabular}

After it was confirmed that no high-level correlation existed between the variables used in DEA, an input-oriented VRS model of DEA was applied. According to the results of the analysis, 13 of the 35 OECD countries (37\%) have efficient healthcare systems, and 22 (63\%) have inefficient healthcare systems. The most frequently referenced healthcare systems among those deemed efficient are the ones in Iceland (19), Turkey (14), and Israel (12) (Table 4). 
Table 4

Variable Returns of DEA Results And Efficient Countries Referenced Compared to Inefficient

Countries According to The Variable Returns to Scale.

\begin{tabular}{|c|c|c|c|c|c|c|c|}
\hline Countries & Score & & & Reference & Countries & & \\
\hline Australia & 0.84671 & Canada & Iceland & Israel & Luxembourg & Spain & \\
\hline Austria & 0.64673 & Iceland & Israel & Luxembourg & Turkey & & \\
\hline Belgium & 0.81668 & Canada & Iceland & Japan & Luxembourg & Turkey & \\
\hline Canada & 1 & & & & & & \\
\hline Chile & 1 & & & & & & \\
\hline Czech Republic & 0.72378 & Iceland & Luxembourg & Turkey & & & \\
\hline Denmark & 0.8749 & Chile & Iceland & Israel & Sweden & & \\
\hline Estonia & 0.82409 & Iceland & Turkey & & & & \\
\hline Finland & 0.87241 & Canada & Iceland & Japan & Luxembourg & Turkey & \\
\hline France & 0.84127 & Canada & Chile & Israel & Japan & & \\
\hline Germany & 0.59132 & Canada & Iceland & Israel & Japan & Luxembourg & Turkey \\
\hline Greece & 1 & & & & & & \\
\hline Hungary & 0.64933 & Iceland & Turkey & & & & \\
\hline Iceland & 1 & & & & & & \\
\hline Ireland & 0.9826 & Canada & Iceland & Israel & Luxembourg & Turkey & \\
\hline Israel & 1 & & & & & & \\
\hline Italy & 0.9827 & Israel & Luxembourg & Spain & & & \\
\hline Japan & 1 & & & & & & \\
\hline Korea & 1 & & & & & & \\
\hline Latvia & 0.77268 & Iceland & Turkey & & & & \\
\hline Luxembourg & 1 & & & & & & \\
\hline Mexico & 1 & & & & & & \\
\hline Netherlands & 0.77939 & Canada & Iceland & Israel & Luxembourg & Turkey & \\
\hline New Zealand & 0.95215 & Canada & Chile & Israel & Spain & & \\
\hline Norway & 0.77992 & Iceland & Israel & Spain & Sweden & & \\
\hline Poland & 0.84995 & Iceland & Japan & Turkey & & & \\
\hline Portugal & 0.79001 & Chile & Iceland & Israel & Mexico & & \\
\hline Slovak Republic & 0.64127 & Iceland & Turkey & & & & \\
\hline Slovenia & 0.90353 & Canada & Iceland & Israel & Japan & Luxembourg & Turkey \\
\hline Spain & 1 & & & & & & \\
\hline Sweden & 1 & & & & & & \\
\hline Switzerland & 1 & & & & & & \\
\hline Turkey & 1 & & & & & & \\
\hline United Kingdom & 0.94874 & Canada & Chile & Iceland & Spain & & \\
\hline United States & 0.84081 & Chile & Iceland & Mexico & Turkey & & \\
\hline
\end{tabular}

As shown in Table 5, the error terms (residuals) used in OLS regressions were distributed normally, and there were no multicollinearity problems between the data, nor were there 
autocorrelation or heteroscedasticity problems. Besides, there is no model establishment error in the OLS regression model.

Table 5

Tests Related to The OLS Regression Model

\begin{tabular}{|c|c|c|}
\hline $\begin{array}{l}\text { Tests Related to the } \\
\text { Model }\end{array}$ & The Test Used, Test Result and Value & Result \\
\hline Normality Test & Jarque-Bera $=0.37, p=0.83>0.05$ & $\begin{array}{l}\text { The error terms } \\
\text { (residuals) are } \\
\text { distributed normally. }\end{array}$ \\
\hline Multicollinearity Test & $\begin{array}{l}\text { For tobac, obez and alch, centered VIF values; } \\
1.14,1.12,1.02 \text {. }\end{array}$ & $\begin{array}{l}\text { Multicollinearity is } \\
\text { insignificant. }\end{array}$ \\
\hline Autocorrelation Test & $\begin{array}{l}\text { Breusch-Godfrey }=\text { Obs*R-squared=2,61, Prob. } \\
\text { Chi-Square }(1)=0.10>0,05\end{array}$ & $\begin{array}{l}\text { There is no } \\
\text { autocorrelation. }\end{array}$ \\
\hline Heteroscedasticity Test & $\begin{array}{l}\text { Breusch-Pagan-Godfrey }=\text { Obs } * \text { R-squared }=1.51 \text {, } \\
\text { Prob. Chi-Square }=0.67>0.05\end{array}$ & $\begin{array}{l}\text { There is no } \\
\text { heteroscedasticity. }\end{array}$ \\
\hline Ramsey Reset Test & F statistic $=2,69 p=0,13>0.05$ & $\begin{array}{l}\text { There is no model } \\
\text { establishment error. }\end{array}$ \\
\hline
\end{tabular}

A test was conducted to investigate the existence of autocorrelation or partial correlation in all lags; no autocorrelation or partial correlation was found (Figure 1).

\begin{tabular}{|c|c|c|c|c|c|c|c|c|}
\hline \multicolumn{2}{|c|}{ Autocorrelation } & \multicolumn{2}{|c|}{ Partial Correlation } & \multicolumn{2}{|r|}{$\mathrm{AC}$} & \multirow{2}{*}{$\frac{\text { PAC }}{-0.256}$} & \multirow{2}{*}{$\frac{\text { Q-Stat }}{2.5042}$} & \multirow{2}{*}{$\begin{array}{l}\text { Prob } \\
0.114\end{array}$} \\
\hline $1 \square$ & I & $1 \square$ & 1 & 1 & -0.256 & & & \\
\hline 它 & 1 & p & I & 2 & 0.110 & 0.048 & 2.9813 & 0.225 \\
\hline I & I & 曰 & I & 3 & 0.129 & 0.180 & 3.6503 & 0.302 \\
\hline$\square$ & 1 & $1 \square$ & I & 4 & -0.293 & -0.248 & 7.2274 & 0.124 \\
\hline & I & I & I & 5 & 0.115 & -0.044 & 7.8012 & 0.168 \\
\hline 1 둥 & I & 1 日 & I & 6 & -0.159 & -0.115 & 8.9278 & 0.178 \\
\hline 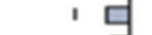 & I & 1 ㅁ & I & 7 & -0.141 & -0.165 & 9.8502 & 0.197 \\
\hline 1 둔 & I & $\square$ & I & 8 & -0.130 & -0.304 & 10.662 & 0.222 \\
\hline $1 \mathrm{p}$ & 1 & 1 & 1 & 9 & 0.067 & 0.050 & 10.883 & 0.284 \\
\hline 10 & I & 1 & I & 10 & -0.066 & -0.051 & 11.109 & 0.349 \\
\hline ' & 1 & 14 & I & 11 & 0.010 & -0.104 & 11.115 & 0.434 \\
\hline ' & I & 1 & I & 12 & 0.177 & 0.051 & 12.886 & 0.377 \\
\hline$\square$ & 1 & 1멸 & I & 13 & -0.268 & -0.257 & 17.112 & 0.194 \\
\hline ' & ני & 19 & 1 & 14 & 0.213 & -0.082 & 19.910 & 0.133 \\
\hline p & I & p & I & 15 & 0.045 & 0.043 & 20.040 & 0.170 \\
\hline I & I & 口 & I & 16 & 0.013 & 0.128 & 20.052 & 0.218 \\
\hline
\end{tabular}

Figure 1. Autocorrelation and Partial Correlation Values of The OLS Regression Model

Table 6, shows the results of the OLS regression analysis which predict the effect of the behavioral risk factor variables on the performance of the healthcare system. Statistical predictions related to the regression model show that the model is generally significant $(F=0.004044 ; p<0.05)$. Together, the behavioral risk factors explain $28 \%$ of the total variation in the performance of the healthcare system. 
Table 6

OLS Regression Results

\begin{tabular}{lcccc}
\hline Variable & Coefficient & Std. Error & t-Statistic & Prob. \\
\hline Tobac & -0.006504 & 0.003922 & -1.658268 & 0.1073 \\
Obes & -0.003897 & 0.003127 & -1.246120 & 0.2221 \\
Alch & -0.025618 & 0.007573 & -3.382938 & 0.0020 \\
C & 1.295016 & 0.118800 & 10.90084 & 0.0000 \\
\hline R-squared & 0.344473 & Mean dependent var & & 0.883171 \\
Adjusted R-squared & 0.281035 & S.D. dependent var & & 0.126350 \\
S.E. of regression & 0.107134 & Akaike info criterion & & -1.522260 \\
Sum squared resid. & 0.355809 & Schwarz criterion & & -1.344506 \\
Log likelihood & 30.63955 & Hannan-Quinn criter. & & -1.460899 \\
F-statistic & 5.430059 & Durbin-Watson stat & & 2.505843 \\
Prob(F-statistic) & 0.004044 & & \\
\hline
\end{tabular}

In the regression model, when the results of the t-test related to the significance of the regression coefficients were analyzed, the only statistically significant relationship was with alcohol. While the use of tobacco, obesity, and alcohol harms the performance of healthcare systems, alcohol has the only significant relation $(\mathrm{p}<0.05)$. An increase in the use of alcohol harms the performance of a healthcare system $(\mathrm{t}=-3.382938 ; \mathrm{p}<0.05)$.

\section{Discussion And Conclusion}

Although healthy lifestyle behaviors have positive effects on society, the question of why these behaviors are not widespread arises, and the importance of the need for changing behavioral risk factors (tobacco, alcohol, obesity), which harm the performance of healthcare systems, is emphasized (Rimer \& Glanz, 2015). Such behavioral risk factors are not only seen as the fundamental reasons behind chronic diseases, but they also increase healthcare costs (Sturm, 2002). Consequently, behavioral risk factors are believed to negatively affect the performance of healthcare systems. Based on this view, this study aims to evaluate the performance of behavioral risk factors on healthcare systems and constitutes an attempt to contribute to the literature on this topic.

A healthy life cannot be separated from behaviors. Studies show that people who are not subjected to behavioral risk factors have a lower rate of death than those who are (Rimer \& Glanz, 2015). For example, in a study focusing on the negative effects of excessive use of alcohol, it is indicated that excessive use of alcohol causes one in every ten deaths among the working population in the USA, and in 2006 this resulted in approximately 223.5 billion dollars in healthcare costs in the USA. Moreover, in the same study, it was found that the excessive use of 
alcohol caused an additional cost of 28 billion dollars to the healthcare system in the USA and 179 billion dollars in the losses of efficiency sustained by its workforce and labor market (Sacks, Gonzales, Boucher, Tomedi \& Brewer, 2015). It is also stated that there were around three million deaths caused by alcohol around the world in 2016, and the number of deaths due to alcohol is greater than the number of deaths due to HIV/AIDS, tuberculosis, and diabetes (WHO, 2018).

The excessive use of alcohol is one of the primary risk factors for human health, and has an effect on many of the objectives (promotion of maternal and child health, eradication of communicable [HIV, hepatitis, and tuberculosis] and noncommunicable diseases, promotion of mental health, treatment of injuries and intoxication) of the Sustainable Development Goals (SDG). The global rates of diseases caused by alcohol use are quite high. It is indicated that excessive use of alcohol causes more diseases than other risk factors, and more than 200 health conditions (from liver diseases to highway injuries, from violence to cancer, cardiovascular diseases, suicides, tuberculosis, and HIV/AIDS) are attributed to the use of alcohol (WHO, 2018).

It is possible to observe the negative effects of excessive alcohol use when the literature is analyzed. In their study, Rabiee et all examined the effect of alcohol on the disease burden with alcohol-related DALYs (Disability Adjusted Life Years) and found that alcohol use caused an increase in alcohol-related DALYs in Russia and India (Rabiee, Agardh, Coates, Allebeck \& Danielsson, 2017). In another study focusing on the monetary effects of alcohol use, Johnston et all estimated that the total financial value of all the damages caused by the use of alcohol was $£$ 7,467 billion (Johnston, Ludbrook \& Jaffray, 2012). In their studies, which investigated the relationship between alcohol use and mortality via a regression model they created, detected a positive relationship between the amount of alcohol use and mortality (Stewart, Han \& Doran, 2017). In addition to these studies, other studies also indicated the possibility of positive effects of low alcohol use on health. For example, Xi et al found that there was an inverse relationship between mortality and a low or reasonable level of alcohol use, and a positive relationship between mortality and excessive alcohol useThe (Xi, Veeranki, Zhao, Ma, Yan \& Mi, 2018). findings of this study are supported by others in the literature. According to the findings of this study, there is a statistically significant negative effect of alcohol consumption on the DEA scores of OECD countries. For this reason, it is asserted that excessive alcohol use harms the performance of healthcare systems. 
By the findings of this study, alcohol, smoking and obesity-causing food consumption habits, harm the performance of healthcare systems. It is believed that effective policies against the consumption of alcohol, tobacco, and overeating will help in protecting public health. Accordingly, particular policies are recommended for the reduction of alcohol use. Among the policies which aim at achieving effective reduction of alcohol use, are those related to pricing alcohol with taxes? Moreover, countries ought to make macro-level policy changes to raise awareness in their societies about the damages of alcohol, tobacco, and obesity. For example, introducing some restrictions on the sales of cigarettes and alcohol and providing healthy eating training programs can be counted among the policy changes that ought to be adopted by countries.

Besides this, more actions can reduce alcohol and cigarette addiction and limit obesity rates. Such actions might include setting an age limit for alcohol sales, more strict restrictions on alcohol advertisements, and more emphasis on community-based healthcare services that are devoted to the treatment of alcoholism. Such actions and measures would positively reflect upon the treatment costs of comorbidities caused by behavioral risk factors which represent serious burdens on health care systems and health expenditures of individuals. Therefore, health managers should take effective steps towards raising awareness about this significant issue for the sake of reducing health expenditures and ensuring better performance of the healthcare systems. 


\section{References}

World Health Organization (WHO) (2000). World health report: Health systems improving performance. Chapter One, Why Do Health Systems Matter? 5-6.

Kruk M. E. \& Freedman L. P. (2008). Assessing health system performance in developing countries: A review of the literature. Health policy, 85, 263-276.

Caballer-Tarazona, M., Moya-Clemente, I., Vivas-Consuelo, D. \& Barrachina-Martínez I. (2010). A model to measure the efficiency of hospital performance. Math Comp Model, 52, 10951102.

Tyagi, A. \& Singh, P. (2017). Hospital performance management: A multi-criteria decisionmaking approach. International Journal of Healthcare Management, 12(4), 286-291. doi: 10.1080/20479700.2017.1337606

Giannini, M. (2015). Performance and quality improvement in healthcare organizations. International Journal of Healthcare Management, 8(3), 173-179. doi: 10.1179/2047971915Y.0000000002.

Joachim, A. \& Adeyemi, K. S. (2017). Performance role models among public health facilities: An application of data envelopment analysis. International Journal of Healthcare Management, 13(3), 193-200. doi: 10.1080/20479700.2017.1397379.

Roberts, M., Hsiao, W., Berman, P. \& Reich, M. (2008). Getting health reform right: A guide to improving performance and equity. Oxford: Oxford University Press.

Papanicolas, I. \& Smith, P. (2013). Health system performance comparison: an agenda for policy, information and research. United Kingdom: McGraw-Hill.

Brown, S., Birtwistle, J., Roe, L. \& Thompson, C. (1999). The unhealthy lifestyle of people with schizophrenia. Psychol. Med, 29, 697-701.

WHO (2017). Noncommunicable diseases: progress monitor 2017. Geneva.

Nuti, S. (2008). La valutazione della performance in sanità. Il Mulino. Italia.

Anderson, G. \& Hussey, P. S. (2001). Comparing health system performance in OECD countries. Health Aff, 20, 219-232.

Charnes, A., Cooper, W. \& Rhodes, E. (1978). Measuring the efficiency of decision making units. Eur J Oper Res., 2, 429-444.

Banker, R. D., Charnes, A., \& Cooper, W. W. (1984). Some Models for Estimating Technical and Scale Inefficiencies in Data Envelopment Analysis. Manag Sci., 30, 1078-1092.

Narc1, H. Ö. (2012). "Efficiency measurement and methods in health institutions", In: Operations management in health institutions, (Editors) Şahin, İ. \& Narc1, H. Ö. Anatolian University Publishing. pp.112-139. Eskişehir. 
Charnes, A., Cooper, W., \& Rhodes, E. (1981). Evaluating program and managerial efficiency: An application of data envelopment analysis to program follow through. Manag Sci, 27, 668697.

Sherman, H. \& Zhu, J. (2006). Service productivity management: Improving service performance using data envelopment analysis (DEA). USA: Springer.

Özcan, Y. (2014). Healthcare benchmarking and performance evaluation. 2nd edition. USA: Springer.

Chern, J. Y. \& Wan, T. T. (2000). The Impact of the prospective payment system on the technical efficiency of hospitals. J Med Syst., 24, 159-172.

Stöckl, D., Dewitte, K. \& Thienpont, L. M. (1998). Validity of linear regression in method comparison studies: Is it limited by the statistical model or the quality of the analytical input data?. Clin Chem, 44, 2340-6.

Rimer, B. K. \& Glanz, K. (2015). Health behavior: Theory, research, and practice. 5th edition. USA: John Wiley \& Sons.

Sturm, R. (2002). The effects of obesity, smoking, and drinking on medical problems and costs. Health Aff., 21, 245-253.

Sacks, J. J., Gonzales, K. R., Bouchery, E. E., Tomedi, L. E. \& Brewer, R. D. (2015). 2010 national and state costs of excessive alcohol consumption. Am J Prev Med., 49(5), 73-79.

WHO (2018). Global status report on alcohol and health 2018. Geneva.

Rabiee, R., Agardh, E., Coates, M. M., Allebeck, P., \& Danielsson, A. K. (2017). Alcoholattributed disease burden and alcohol policies in the BRICS-countries during the years 1990-2013. Journal of Global Health., 7, 1-8.

Johnston, M. C., Ludbrook, A. \& Jaffray, M. A. (2012). Inequalities in the distribution of the costs of alcohol misuse in Scotland: A cost of illness study. Alcohol and Alcoholism, 47(6), $725-$ 731.

Stewart, D., Han, L., Doran, T. \& McCambridge, J. (2017). Alcohol consumption and all-cause mortality: An analysis of general practice database records for patients with long-term conditions. J Epidemiol Community Health, 71(8), 729-735.

Xi, B., Veeranki, S. P., Zhao, M., Ma, C., Yan, Y. \& Mi, J. (2017). Relationship of alcohol consumption to all-cause, cardiovascular, and cancer-related mortality in US adults. $J \mathrm{Am}$ Coll Cardiol., 70(8), 913-922. 